\title{
Diagnóstico inmunohistoquímico del dengue en cortes de parafina
}

\author{
Ladys Sarmiento', Gerzaín Rodríguez², Jorge Boshell ${ }^{3}$
}

\begin{abstract}
Resumen
La demostración de antígenos de los virus del dengue en tejidos de pacientes fallecidos por dengue hemorrágico y particularmente en aquellos casos en los que no se dispone de otras pruebas para confirmar la etiología viral, es una necesidad frecuente en nuestro medio. Por esta razón, estandarizamos una técnica inmunohistoquímica para detectar antígenos de dengue en tejidos incluidos en parafina. Utilizamos anticuerpos antiflavivirus comúnmente usados para el diagnóstico serológico. Los antígenos empleados para estandarizar esta técnica incluyeron: 1) cerebros de ratón inoculados con los diferentes serotipos del dengue y con virus de la fiebre amarilla; 2) cortes de hígados de pacientes fallecidos con diagnóstico clínico de dengue hemorrágico, fiebre amarilla o hepatitis delta; y, 3) monocapas de células $66 / 36$ inoculadas también con los diferentes serotipos del dengue. Estos antígenos se enfrentaron a los anticuerpos antiflavivirus (fiebre amarilla o dengue) preparados como líquidos ascíticos inmunes (LAl) de ratón, siguiendo procedimientos ya establecidos. Utilizamos LAI preparados en el INS y LAl suministrados por la OPS.

La dilución ideal de trabajo con la cual pudimos observar la presencia del antígeno, tanto en los tejidos como en las células, se obtuvo titulando los distintos LAl frente a cortes de tejido desparafinado o frente a las células fijadas en etanol sobre la lámina de vidrio. Con los LAl preparados en el INS, observamos reacción cruzada entre todos los flavivirus, resultado que no se observó en los cortes de hígado con diagnóstico de hepatitis delta. Los resultados obtenidos con los LAI de la OPS permitieron visualizar los antígenos virales más claramente y a diluciones más altas, sin la reacción cruzada entre el dengue y la fiebre amarilla. Sin embargo, la visualización de los mismos con los LAI del INS es satisfactoria y con disponibilidad permanente. La reacción cruzada entre los virus del dengue y de la fiebre amarilla no es un problema mayor en el tejido porque la histopatología de las dos entidades en el hígado, es muy diferente.
\end{abstract}

1 Bacterióloga, Laboratorio de Patología, INS.

2 Coordinador de investigaciones, Laboratorio de Patología, INS; Profesor Titular de cátedra, Departamento de Patología, Facultad de Medicina, Universidad Nacional de Colombia.

3 Coordinador de investigaciones, Laboratorio de Virologia, iNS.

Proyecto 21012-4 


\section{Summary}

In our country it is frequently necessary to confirm the presence of dengue viruses in tissue taken from patients suffering from hemorrhagic dengue and, particulary, in those cases where no other test is available to confirm viral etiology. Therefore, we are standardising an immunohistochemical technique to detect dengue antigens in paraffin fixed tissue. We used anti-flavivirus antibodies commonly used in serological diagnosis. The antigens used in this technique include: 1) rats' brains innoculated with different dengue serotypes and with yellow fever virus; 2) liver sections taken from patients diagnosed as suffering from hemorrhagic dengue, yellow fever or hepatitis delta; and, 3) $C 6 / 36$ single-layer cells also innoculated with different dengue serotypes. These antigens were confronted by anti-flavivirus antibodies (yellow fever or dengue) prepared from rats as immune ascitic liquids (IAL), following already established procedures. We used IAL prepared in the INS and, also, IAL supplied by PAHO.

The ideal dilution in which it is possible to observe the antibodies' presence, in both the tissue as well as the cells, was obtained by titering the distinct IAL to confront the deparaffined tissue or to confront cells mounted on glass microscope sections, fixed in ethanol. With IAL prepared in the INS we observe a cross-reaction amongst the flavivirus, a result which was not observed in the liver sections from patients diagnosed as having hepatitis delta. Results obtained from the IAL provided by PAHO allowed clearer viewing of viral antigens and greater dilution without the cross-reaction between dengue and yellow fever. However, viewing the same using IAL form the INS is satisfactory and this source of IAL is permanently available. The cross- reaction between the dengue and the yellow fever virus is not a major problem in tissue because the histopathology of the two entities, in the liver, is very different.

Varias enfermedades infecciosas, merced a su gravedad o a su importancia epidemiológica, exigen que el diagnóstico clínico sea confirmado por el laboratorio. El dengue es un ejemplo típico, que analizamos en el presente trabajo.

La sospecha clínica de dengue se confirma en el laboratorio mediante cinco procedimientos fundamentales:

1. Aislamiento e identificación del virus a partir del suero tomado en la fase aguda de la enfermedad (1-5).

2. Pruebas serológicas como inhibición de la hemaglutinación, fijación del complemento o neutralización que permiten demostrar un incremento de anticuerpos en la fase convaleciente de la enfermedad, en comparación con la fase aguda de la misma (1-5).

3. Detección de IgM antiflavivirus en sueros de la fase aguda o subaguda de la enfermedad, utilizando pruebas inmunoenzimáticas de tipo
$\operatorname{ELISA}(2,3,5)$. Estas pruebas ofrecen la ventaja de permitir el diagnóstico con un suero único. En algunos laboratorios se utiliza este sistema ELISA para detectar IgG e IgM antiflavivirus y establecer una relación IgG/ IgM que permite identificar reacciones secundarias.

4. Pruebas moleculares destinadas a detectar fracciones del genoma viral en los leucocitos infectados (v.gr., sondas de DNA/RNA, amplificación genética del tipo de la reacción en cadena de la polimerasa o la combinación de ambas) (6-8).

5. Aunque no es de uso rutinario, la inoculación intracerebral del ratón lactante con algunas cepas de virus del dengue (9), origina una encefalitis discreta, con desarrollo viral intraneural demostrable por microscopía electrónica y por técnicas inmunohistoquímicas.

Algunas condiciones pueden complicar un poco el manejo de las muestras de las cuales se va a 
aislar el virus: deben conservarse frescas, a baja temperatura $\left(4^{\circ} \mathrm{C} 0-20^{\circ} \mathrm{C}\right)$; además, los cambios de temperatura durante la congelación y descongelación definitivamente afectan la conservación viral (10). Estas condiciones no son fáciles de llenar en las áreas suburbanas o en poblaciones pequeñas alejadas de los centros de referencia.

El desarrollo de métodos para la demostración del antígeno utilizando marcadores fluorescentes o enzimáticos, aplicados a muestras incluidas en parafina, tiene la mayor importancia en los casos de la variedad hemorrágica, urgencia médica y epidemiológica a veces letal, en donde, con mucha frecuencia, el único material disponible para confirmar el diagnóstico es el tejido obtenido en la autopsia (11-12).

En este trabajo comunicamos la estandarización de una técnica inmunohistoquímica para detectar antígenos de los virus del dengue en tejidos incluidos en parafina, utilizando los anticuerpos comúnmente usados para el diagnóstico serológico, producidos en el Laboratorio de Virología del INS.

\section{Materiales y métodos}

\section{Tejidos}

Se inocularon intracerebralmente cuatro grupos de cinco ratones lactantes cada uno. Cada grupo se inoculó con un serotipo distinto de virus del dengue, de las cepas prototipo que se mantienen en el Laboratorio de Virología del INS. Al quinto día, los animales se sacrificaron, el cerebro se fijó en formol tamponado neutro y se incluyó en parafina.

Se utilizaron además como controles positivos, fragmentos de hígado y bazo, incluidos en parafina, provenientes de una niña de 13 años, fallecida por dengue hemorrágico. Estos bloques fueron seleccionados de los archivos del Laboratorio de Patología del INS.

Con el fin de determinar la especificidad de los anticuerpos frente a otras patologías, se utilizaron cortes de hígado incluidos en parafina y diagnosticados como hepatitis delta y fiebre amarilla, así como muestras de cerebro de ratón con encefalitis experimental por el virus vacunal de la fiebre amarilla.

Las reacciones inespecíficas se evaluaron con cortes de control de los mismos tejidos, a los cuales no se adicionó el anticuerpo primario.

\section{Células}

Cultivos de la línea celular $\mathrm{C} 6 / 36$ se inocularon cada uno con un diferente serotipo del dengue y se incubaron durante 5 días a $37^{\circ} \mathrm{C}(13-15)$. Después de desprender la monocapa con golpes suaves, las células se centrifugaron con el fin de separarlas del medio de cultivo.

Se hizo un extendido celular que se fijó con etanol al $95 \%$ y se continuó con el proceso inmunocitoquímico, análogo al realizado con los tejidos. Al final, no se realizó contraste con hematoxilina para poder observar mejor la inmunorreactividad.

Este material se utilizó como control adicional de la calidad de los anticuerpos empleados.

\section{Anticuerpos}

Se utilizaron dos fuentes de anticuerpos policlonales:

1. Líquido ascítico inmune (LAI) de ratón preparado en el INS, siguiendo la técnica de Clarke y Casals (16). Estos LAI se utilizan rutinariamente como controles en las pruebas de inhibición de la hemaglutinación para el diagnóstico serológico de la enfermedad y tienen especificidad de grupo para todos los flavivirus. Se utilizaron tres LAl preparados con inóculos de dengue tipo 1,2 y 4 respectivamente. Todos dieron reacciones similares tanto en el tejido como en las células.

2. La policlonal anti-dengue tipo 2 , el cual presenta reacción cruzada contra los cuatro tipos de virus del dengue, sin presentarla para el virus de la fiebre amarilla (12), anticuerpo donado por la OPS en un taller organizado en octubre de 1990, sobre el diagnóstico de la fiebre amarilla y el dengue, en el Instituto Evandro Chagas (Belem, Pará, Brasil).

\section{Método inmunohistoquímico}

En primer lugar, se utilizó el anticuerpo policlonal anti-dengue tipo 2 donado por la OPS, para confirmar la presencia de antígeno tanto en los cerebros de ratón como en las células $\mathrm{C6} / 36$. Una vez confirmada la presencia de antígeno viral en las muestras, se procedió a titular el LAI del INS. 
A partir de las muestras fijadas en formol e incluidas en parafina, se realizaron cortes de 5 micras de espesor. Estos se recogieron en láminas con adhesivo Poly- $L-L y$ sine (Sigma Cat. No. $\mathrm{P} 8920)$ y se dejaron a $55-60^{\circ} \mathrm{C}$ durante toda la noche para luego desparafinizarlos realizando tres cambios de tres minutos cada uno en xilol. Inmediatamente se hizo una rehidratación y digestión enzimática de los cortes utilizando una proteasa tipo III (Sigma, Cat. B5380) al 0,5\%, a $37^{\circ} \mathrm{C}$ con $\mathrm{pH}$ de 7,8 , durante tres minutos, después de lo cual se lavaron en agua realizando tres cambios de dos minutos cada uno. Se bloquearon las reacciones inespecíficas de fondo, utilizando suero normal de caballo diluido 1:200, durante 30 minutos, en cámara húmeda, en donde se realizaron todas las incubaciones.

En las muestras de hígado se realizó bloqueo de la biotina endógena agregando avidina por 15 minutos, lavando y agregando biotina por otros 15 minutos. Finalmente se agregó el suero normal de caballo y, después de retirarlo, se agregó el anticuerpo primario anti-dengue el cual se dejó actuar durante 1 hora. Terminada esta incubación el anticuerpo, se lavó con PBS realizando tres cambios por tres minutos cada uno y, finalmente, se aplicó el anticuerpo secundario IgG anti-ratón, elaborada en caballo y marcada con biotina (Vector Lab. Cat. No. BA2000), durante 1 hora a la dilución de 1:20. Nuevamente se realizaron tres cambios en PBS e inmediatamente se agregó el complejo estreptavidina-fosfatasa alcalina (Pierce Cat. No. 21323) en una dilución de 1:100, durante 1 hora.

Como sustrato cromógeno se utilizó Histomark red (Kirkergaard and Perry Labs. Cat. No. 7100) y levamisol para inhibir la fosfatasa alcalina endógena, durante 1 hora; las láminas se lavaron luego con agua destilada realizando dos cambios de tres minutos cada uno; se contrastaron con hematoxilina por dos minutos; se deshidrataron en una serie creciente de alcoholes; se pasaron rápidamente por xilol $\mathrm{y}$, después de montarse utilizando un sellante (citorresina), se observaron al microscopio de luz.

El extendido de las células $\mathrm{C} 6 / 36$ infectadas con los virus del dengue, se sometió a un proceso análogo, sin usar la pronasa.

\section{Resultados}

La presencia de antígeno de virus del dengue se demostró por medio del líquido ascítico policlonal anti-dengue tipo 2 donado por la OPS, en las neuronas de los cerebros de ratón inoculados con el virus, en las células de Kupffer de la paciente fallecida por dengue hemorrágico, en algunos macrófagos esplénicos y en las células C6/36. La reacción tiñe de rojo el citoplasma de las células que tienen los antígenos virales, que contrasta con el color azul del resto del tejido, dado por la hematoxilina.

Los ensayos de la técnica inmunohistoquímica a diferentes diluciones con los anticuerpos obtenidos en el INS, permitieron encontrar la dilución ideal del anticuerpo primario para las posteriores determinaciones. La selección de la dilución adecuada se basó en la nitidez de las láminas en la lectura final, un resultado positivo bien definido y un contraste claro entre controles positivos y controles negativos (figuras 1-3).

En el cerebro de ratón puede existir alguna reacción inespecífica de fondo o en los vasos, debida a la interacción de las inmunoglobulinas murinas con el anticuerpo secundario elaborado contra el ratón. Por esta razón, se corrieron conjuntamente controles negativos para poder comparar las láminas y evitar resultados falsos positivos. Estos controles se procesaron de forma idéntica, pero no se les adicionó el anticuerpo primario. De manera similar se demostró la presencia del antígeno viral en las células C6/36 (figura 3).

Al hacer reaccionar los $\mathrm{LAl}$ anti-dengue del INS con cerebros de ratón inoculado con el virus de la fiebre amarilla y con hígados humanos con la misma entidad, se obtuvo inmunorreactividad positiva bien definida, reacción cruzada que no se observa cuando se utiliza el anticuerpo policlonal anti-dengue tipo 2 de la OPS. En los hígados con diagnóstico de hepatitis delta, no hubo reacción cruzada alguna.

La falta de un número adecuado de muestras de hígados de pacientes con diagnóstico confirmado de dengue por aislamiento viral impidió la evaluación adecuada de la sensibilidad del procedimiento. 


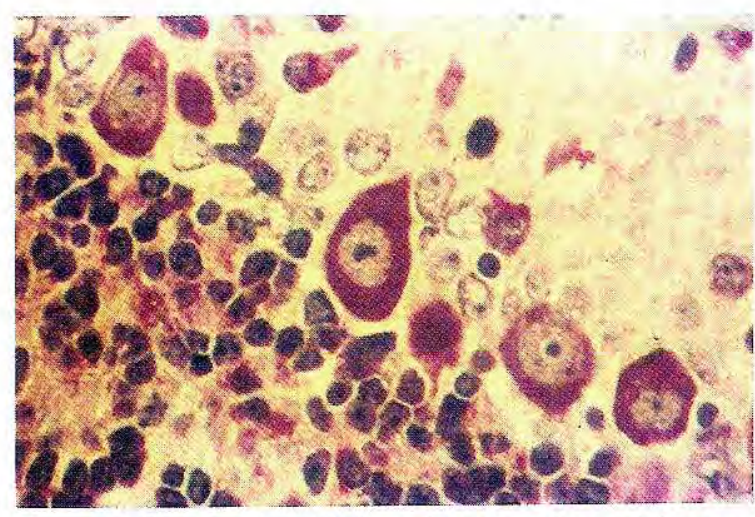

Figura 1. Cerebro de ratón inoculado con virus del dengue. Reacción positiva con técnica inmunohistoquímica; citoplasma teñido de rojo; LAl del INS (400X).

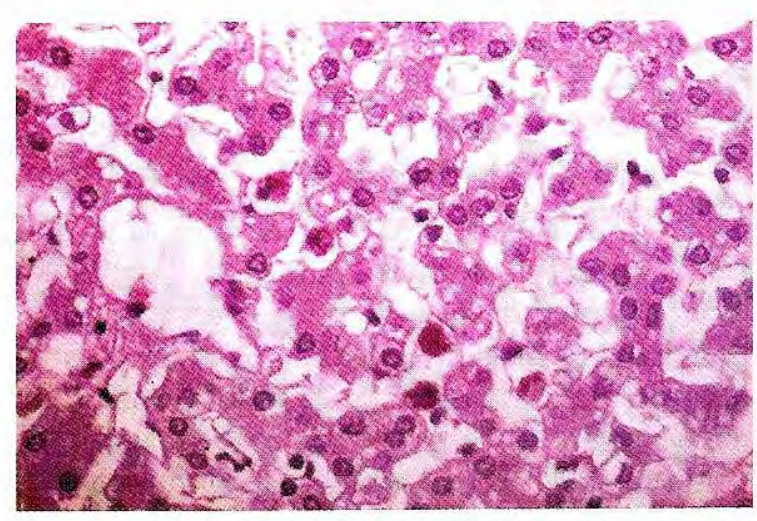

Figura 2. Hígado humano. Reacción positiva para virus del dengue en las células de Kupffer; caso control con LAI del INS (400X).

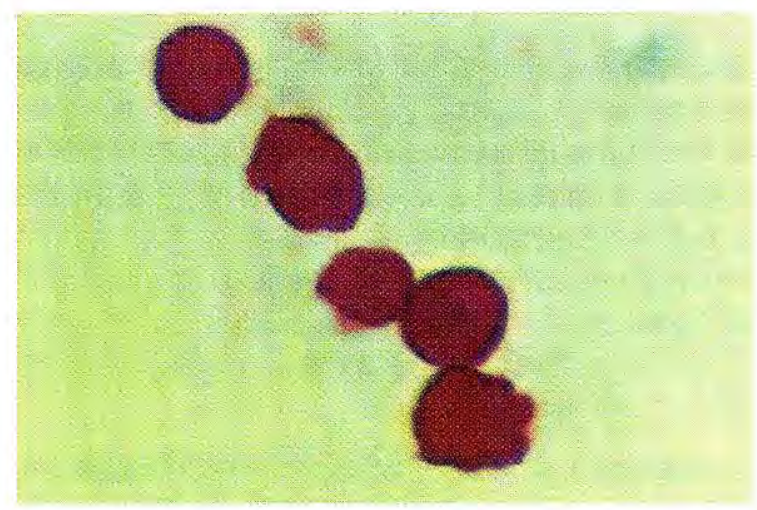

Figura 3. Células $\mathrm{C} 6 / 36$ infectadas con virus del dengue. La inmunorreactividad positiva con LAI del INS se ve de color rojo intenso (100X).

\section{Discusión}

Los resultados obtenidos indican que los anticuerpos preparados en el INS y usados para realizar el diagnóstico serológico del dengue pueden ser utilizados en tejidos incluidos en parafina. Como era de esperarse, muestran el mismo comportamiento que en las reacciones serológicas: dan reacción cruzada con el virus de la fiebre amarilla y no distinguen entre sí los serotipos del dengue.

Los anticuerpos también pueden utilizarse para estudio de hígados incluidos en parafina, correspondientes a casos de fiebre amarilla. Esta inespecificidad, si bien inconveniente, tiene su utilidad en demostrar los antígenos del virus del dengue en pacientes que fallezcan por dengue hemorrágico y en los que no se dispone de otras pruebas para confirmar la etiología viral. El procedimiento debe ayudarse de la imagen histológica usual a la hematoxilina-eosina, en el hígado, que es característica en más del $90 \%$ de los casos de fiebre amarilla (5). Tanto en nuestra experiencia como en lo informado en la literatura (17), la histopatología del dengue en el hígado no se confunde en la mayoría de los casos, con aquélla de la fiebre amarilla.

Si bien los LAI suministrados por la OPS para uso en tejido tanto para dengue como para fiebre amarilla $(12,18)$ son los más específicos, los producidos en el INS constituyen una herramienta útil, accesible, de fácil manejo, con la misma eficiencia en los tejidos que la alcanzada en el diagnóstico de tamizaje global en los sueros de los enfermos con clínica sospechosa de dengue.

\section{Agradecimientos}

A la bacterióloga Laura Sofía de Calderón, del Laboratorio de Virología del INS por su colaboración en la inoculación de los animales experimentales y las células $\mathrm{C} 6 / 36$.

A la bacterióloga Gloria Patricia Barrera del Laboratorio de Patología por su colaboración en la realización del trabajo.

A las bacteriólogas Adriana García y María Mercedes Hidalgo quienes ayudaron en la estandarización de las técnicas presentadas, como parte de su trabajo de tesis de pregrado. 


\section{Referencias}

1. Manson B. Tropical diseases. London: Bailliere Tindal, 1982:271.

2. Monath TP. Dengue. In: Mahmound AAF, ed. Tropical and geographical medicine. New Jersey: McGraw-Hill Inc., 1990:661.

3. Organización Mundial de la Salud. Dengue hemorrágico: diagnóstico, tratamiento y lucha. Ginebra: OMS, 1986.

4. Ministerio de Salud. Plan de vigilancia y control para fiebre amarilla y dengue. Boletín epidemiológico nacional (Colombia) 1985:11.

5. Groot $\mathbf{H}$, Boshell J. Dengue, dengue hemorrágico y fiebre amarilla. En: Chalem F, Escandon J, Campos J, Esguerra R, eds. Medicina interna, vol. II, segunda edición. Bogotá: Editorial Presencia Ltda., 1992:1389.

6. Killen $\mathrm{H}, \mathrm{O}$ ' Sullivan MA. Detection of dengue virus by in situ hybridization. J Virol Methods 1993;41:135-46.

7. Lanciotti RS, Calisher CH, Gubler DJ, et al. Rapid detection and typing of dengue viruses from clinical samples by using reverse transcriptase-polymerase chain reaction. J Clin Microbiol 1992;30:545.

8. Deubel V, Laille M, Hugnot JP, et al. Identification of dengue sequences by genomic amplification: rapid diagnosis of dengue virus serotipes in peripheral blood. $\mathrm{J}$ Virol Methods 1990;30:41.

9. Hotta H, Murakami I, Miyasaki K, et al. Localization of dengue virus in nude mice. Microbiol Immunol 1981;25:8993.
10. OMS-OPS. Dengue. Cinta fija No. 57.

11. Barth OM, Mejerowicz S, Menasce LP, et al. Detection of viral infection by immunofluorescence in formalin fixed tissues, pretreated with trypsin. Mem Inst Oswaldo Cruz 1988;83:207.

12. Hall W, Ceowell T, Watts D, et al. Demonstration of yellow fever and dengue antigens in formalin-fixed paraffinembedded human liver by immunohistochemical analysis. Am J Trop Med Hyg 1991;45:408.

13. Igarashi A. Characteristics of Aedes albopictus cells persistently infected with dengue viruses. Nature 1979;280:690.

14. Tesh R. A method for the isolation and identification of dengue viruses, using mosquito cell cultures. Am J Trop Med Hyg 1979;28:1053.

15. Barth OM. Replication of dengue viruses in mosquito cell cultures. Mem Inst Oswaldo Cruz 1992;87:565.

16. Clarke DH, Casals J. Techniques for hemagglutination and hemagglutination inhibition with arthropod-borne viruses. Am J Trop Med Hyg 1958;7:561.

17. Torres E. Dengue hemorrágico en niños. Bogotá: Instituto Nacional de Salud, 1990.

18. Ricaurte O, Sarmiento L, Caldas M, Rodríguez G. Evaluación de un método inmunohistoquímico para el diagnóstico de la fiebre amarilla. Biomédica 1993;13:15. 